\title{
Barriers and facilitators for treatment-seeking for mental health conditions and substance misuse: multi-perspective focus group study within the military - CORRIGENDUM
}

Rebecca Bogaers, Elbert Geuze, Jaap van Weeghel, Fenna Leijten, Dike van de Mheen, Piia Varis, Andrea Rozema and Evelien Brouwers

\section{Keywords}

Mental health conditions; substance misuse; treatment gap; stigma; military; corrigendum.

\section{Copyright and usage}

(C) The Author(s), 2021. Published by Cambridge University Press on behalf of the Royal College of Psychiatrists. This is an Open Access article, distributed under the terms of the Creative Commons Attribution licence (http://creativecommons.org/licenses/by/4.0/), which permits unrestricted re-use, distribution, and reproduction in any medium, provided the original work is properly cited.

https://doi.org/10.1192/bjo.2020.136, Published online by Cambridge University Press, 25 November 2020
This article refers incorrectly to the affiliation of author Evelien Brouwers. The correct affiliation for this author is Tranzo, Scientific Center for Care and Wellfare, Tilburg School of Social and Behavioral Sciences, Tilburg University.

\section{Reference}

Bogaers R, Geuze E, van Weeghel J, Leijten F, van de Mheen D, Varis P, Rozema A, Brouwers $E$. Barriers and facilitators for treatment-seeking for mental health conditions and substance misuse: multi-perspective focus group study within the military. BJPsych Open 2020; 6: e146. 